\title{
Curative resectability of gastrointestinal cancer identified from iron deficiency anemia
}

\author{
KENTA KAWASAKI $^{1,2}$, YASUO HAMAMOTO ${ }^{3 *}$, MASAYASU HORIBE ${ }^{2 *}$, KENJI SHIMURA ${ }^{1}$, \\ AKIRA NAKAMURA $^{1}$, TAKANORI KANAI ${ }^{2}$ and HIROMASA TAKAISHI ${ }^{3}$ \\ ${ }^{1}$ Department of Gastroenterology, Asahi General Hospital, Asahi, Chiba 289-2511; \\ ${ }^{2}$ Division of Gastroenterology and Hepatology, Department of Internal Medicine; \\ ${ }^{3}$ Keio Cancer Center, Keio University School of Medicine, Shinjuku, Tokyo 160-8582, Japan
}

Received October 13, 2015; Accepted February 17, 2017

DOI: $10.3892 / 01.2017 .6650$

\begin{abstract}
The present study aimed to clarify the staging and curative resectability of gastrointestinal cancer found through iron deficiency anemia (IDA). An electronic database was used and females $>51$ and males $>18$ years old were identified who had been diagnosed with IDA at the internal medicine outpatient clinic of Asahi General Hospital (Chiba, Japan) from 1 April 2010 to 31 March 2012. IDA was defined as a hemoglobin level of $<135 \mathrm{~g} / 1$ for males and $<120 \mathrm{~g} / 1$ for females, combined with a serum ferritin level of $<33.71 \mathrm{pmol} / \mathrm{l}$. Of the 472 patients who had been diagnosed with IDA, 347 patients underwent either a gastroscopy and/or colonoscopy, including 120 patients who had undergone both gastroscopy and colonoscopy, 197 patients who only underwent gastroscopy, and 30 patients who only underwent colonoscopy. In total, 125/472 patients diagnosed with IDA did not undergo a gastroscopy or a colonoscopy. From the 50 patients who were diagnosed with cancer as a result of the investigation, 24 patients had gastric cancer and 23 patients had colorectal cancer. Of the gastric cancer patients, 6 patients were stage I, 3 patients stage II, 5 patients were stage III and 9 patients were stage IV. In colorectal cancer, 9 patients were stage II, 8 patients were stage III and 4 patients were stage IV. Curative surgery including endoscopic treatment was performed on 14 gastric cancer patients and 17 colorectal cancer patients of stage III or lower. Malignancies were found in 50 patients with IDA, and curative surgery was performed on $>50 \%$ of the patients.
\end{abstract}

Correspondence to: Dr Hiromasa Takaishi, Keio Cancer Center, Keio University School of Medicine, Shinanomachi 35, Shinjuku, Tokyo 160-8582, Japan

E-mail: takaishi@z6.keio.jp

*Contributed equally

Key words: gastrointestinal malignancy, gastric cancer, colorectal cancer, resectability, iron deficiency anemia

\section{Introduction}

Iron deficiency anemia (IDA) is reported to occur in $2-5 \%$ of men and postmenopausal women in the developed world (1). Complete endoscopic investigation is recommended, since gastrointestinal cancer occurs in $10-20 \%$ of IDA patients (2-7). Despite this recommendation, only $30-50 \%$ of patients who are diagnosed with IDA receive an endoscopic examination within 4 months $(8,9)$. This cannot be explained as the patient's unwillingness for treatment, as it is common in daily practice for patients undergoing treatment for IDA to have received no investigation for the potential cause (10). Based on this data, interventions besides the aforementioned recommendation are required for a change in daily practice (8). The importance of IDA must be recognized, as IDA-associated diagnostic testing is one of the most underutilized diagnostic opportunities in colorectal cancer (11). Although the importance of IDA examination is emphasized as an opportunity to identify gastrointestinal cancer, there are only a small number of reports regarding the staging and resectability of gastrointestinal cancer identified through diagnosis of IDA (12).

Japan has a national health insurance system that promotes annual medical check-ups, and is one of the very few countries with a medical system that is prepared for daily endoscopic examinations in municipal hospitals and clinics. Data on endoscopy has been accumulated by hospitals in Japan; however, there are no studies about the staging and resectability of gastrointestinal cancer cases that are identified during the examination of patients with IDA in Japan. The present study was conducted to profile the gastrointestinal cancer cases identified during examination of IDA patients, in order to re-emphasize the importance of IDA examination and confirm the rate of gastrointestinal cancer detection from the examination of IDA patients in a municipal hospital in Japan.

\section{Patients and methods}

Inclusion criteria. Patients (including females $>51$ and males $>18$ years old) who were diagnosed with IDA at the internal medicine outpatient clinic of Asahi General Hospital 
(Chiba, Japan) between 1 April 2010 and 31 March 2012 were included in the retrospective study. Data of these 472 patients were extracted and analyzed. Excel 2013 (Microsoft Corporation, Redmond, WA, USA) was used to calculate means and standard deviation for the data. The diagnosis of IDA was made based on hemoglobin levels $<135 \mathrm{~g} / \mathrm{l}$ for men, and $<120 \mathrm{~g} / \mathrm{l}$ for women, combined with a serum ferritin level of $<33.71 \mathrm{pmol} / 1(15 \mathrm{ng} / \mathrm{ml})(13,14)$. IDA patient data and details of examinations were selected from electronic patient records, and information regarding staging, treatment and clinical course were extracted for each patient diagnosed with cancer.

Exclusion criteria. The exclusion criteria were as follows: Patients who had not received any investigation for gastroscopy or colonoscopy; females who were still undergoing menstruation; patients who had a previous diagnosis for malignancy including recurrence; and patients who had recently undergone phlebotomy (Fig. 1).

Staging of cancer. Patients who were diagnosed with a gastrointestinal malignancy were staged according to the 'tumor, node, metastasis' (TNM) classification of malignant tumors from the International Union Against Cancer, seventh edition, which is based on three factors: primary tumor size, regional lymph node infiltration, and distant metastasis (15). The definition of curative treatment was curative surgery of stage I-III gastric or colorectal cancer $(16,17)$.

Ethics of the study. Approval for the study was obtained from the hospital ethics committee of Asahi General Hospital. Information regarding the study was provided to patients through the hospital website, including the option to opt out. The study was retrospective, so consent was not obtained prior to the study; however, all data was anonymized.

\section{Results}

Causes of IDA. Of the 472 patients (239 men and 233 women) who were diagnosed with IDA, 125 were omitted according to the exclusion criteria (Fig. 1). In total, 347 patients at Asahi General Hospital were enrolled in the study (Table I), of which 152 patients $(44 \%)$ were diagnosed by chance at the daily outpatient clinic during treatment for other conditions, and 195 (56\%) had visited the hospital for specific symptoms or a check-up. The specific symptoms included edema, shortness of breath, palpitation, dizziness, loss of appetite, loss of consciousness and fever. In total, 120 patients (25.4\%) underwent both gastroscopy and colonoscopy, 197 patients (41.7\%) only underwent gastroscopy and 30 patients $(6.4 \%)$ only underwent colonoscopy as part of their IDA examination. Causes of IDA in this cohort are shown in Table II.

Characteristics of cancer patients. A total of 50 (14.4\%) cases of IDA in patients were caused by malignancy; other causes included polyps, papilla tumor and ischemic colitis. The characteristics of patients for whom cancer was the cause of IDA are shown in Table I; 24 patients had gastric cancer and 23 patients had colorectal cancer. Other cancer types included 1 case of esophageal cancer and 2 of lymphoma. In total, $30 \%$

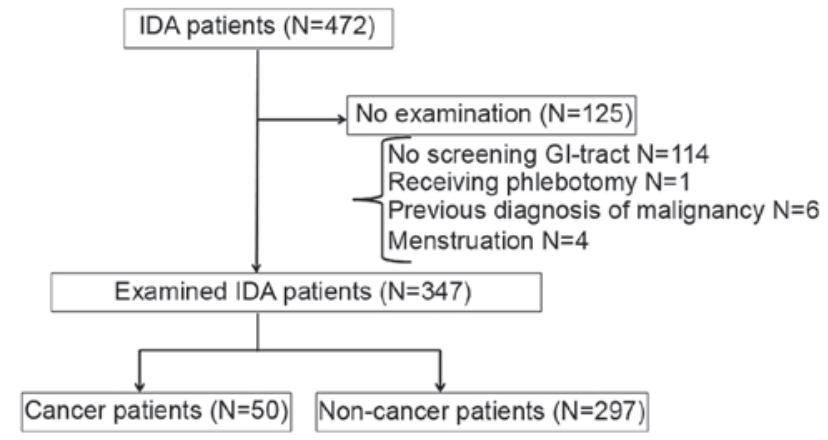

Figure 1. Consort diagram. A total of 347 patients were enrolled in the study. GI, gastrointestinal; IDA, iron deficiency anemia.

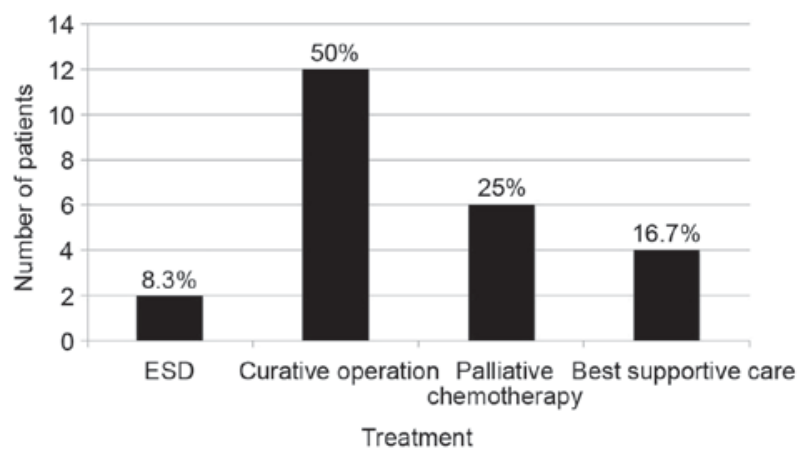

Figure 2. Treatment for gastric cancer. From a total of 24 patients identified as having gastric cancer in the present study, 14 patients (58.3\%) underwent curative ESD or surgery, 6 patients were administered palliative chemotherapy, and 4 patients received best supportive care. ESD, endoscopic submucosal dissection.

of the patients diagnosed with cancer were asymptomatic, while others experienced symptoms including shortness of breath, dizziness and loss of appetite.

Staging and curative resectability. The number of patients for each stage is shown in Table III. Curative surgery, including endoscopic treatment, was performed on 14 gastric cancer patients (58.3\%) and 17 colorectal cancer patients (74.0\%). Subsequently, 1 gastric cancer patient and 2 colorectal cancer patients refused further examination for staging. The treatment results of cancer patients are shown in Figs. 2 and 3.

\section{Discussion}

The present study is the first report on the staging and resectability of gastrointestinal cancer cases identified following the examination of patients with IDA in Japan. The present study revealed that a full investigation for the cause of IDA occurs in $<30 \%$ of cases in the practice. Despite the low frequency of investigation, investigations that were performed demonstrated that malignancy was the cause of IDA in 50 patients $(14.4 \%)$, which is in accordance with data in previous studies $(2,5,18)$.

Given that colorectal cancer is observed at a much higher rate compared with gastric cancer in Western countries, recommendations often suggest a colonoscopy should be performed at first for IDA patients who are $>50$ years of age, 
Table I. Characteristics of patients.

\begin{tabular}{lccccc}
\hline Characteristics & All patients & All cancer types & Gastric cancer & Colorectal cancer & Other cancer \\
\hline $\begin{array}{l}\text { Total, } \mathrm{n} \\
\text { Sex, } \mathrm{n}(\%)\end{array}$ & 347 & 50 & 24 & 23 & 3 \\
$\quad$ Male & $193(55.6)$ & $29(58)$ & $18(75)$ & $8(35)$ & $3(100)$ \\
Female & $154(44.4)$ & $21(42)$ & $6(25)$ & $15(65)$ & $0(0)$ \\
Age, mean years \pm & $68.5 \pm 12.5$ & $74.3 \pm 9.03$ & $73.5 \pm 6.62$ & $76.7 \pm 9.07$ & $62.7 \pm 13.9$ \\
standard deviation & & & & & \\
$\quad$ Males & $65.9 \pm 13.3$ & $72.9 \pm 8.30$ & $74.1 \pm 6.40$ & $74.1 \pm 6.39$ & $62.7 \pm 13.9$ \\
Females & $71.7 \pm 10.7$ & $76.2 \pm 9.64$ & $71.5 \pm 6.87$ & $78.1 \pm 9.95$ & - \\
Reason for visit, $\mathrm{n}(\%)$ & & & & & 0 \\
Outpatient clinic & $152(43.8)$ & $8(16.0)$ & $4(16.7)$ & $4(17.4)$ & 0 \\
Examination for anemia & $81(23.3)$ & $9(18.0)$ & $2(8.33)$ & $7(30.4)$ & 0 \\
Abdominal symptoms & $30(8.65)$ & $21(42.0)$ & $12(50.0)$ & $9(39.1)$ & 0 \\
Fecal occult blood & $2(0.576)$ & $1(2.00)$ & 0 & $1(4.35)$ & $3(100)$ \\
Others & $82(23.6)$ & $11(22.0)$ & $6(25.0)$ & $2(8.70)$ & \\
\hline
\end{tabular}

Table II. Causes of IDA.

\begin{tabular}{lr}
\hline Causes of IDA & Patients, n (\%) \\
\hline All & $347(100)$ \\
Unknown & $148(42.3)$ \\
Malignancy & $50(14.3)$ \\
Gastrointestinal bleeding & $50(14.3)$ \\
Post-gasterectomy & $41(11.7)$ \\
Hemorrhoid & $17(4.86)$ \\
Esophageal varices & $12(3.43)$ \\
Inflammatory bowel disease & $5(1.43)$ \\
Others & $24(6.86)$ \\
\hline
\end{tabular}

IDA, iron deficiency anemia.

Table III. Staging of cancer patients.

\begin{tabular}{lcc}
\hline Staging & $\begin{array}{c}\text { Gastric cancer, } \\
\mathrm{n}(\%)\end{array}$ & $\begin{array}{c}\text { Colorectal cancer, } \\
\mathrm{n}(\%)\end{array}$ \\
\hline All & 23 & 21 \\
I & $6(26.1)$ & $0(0)$ \\
II & $3(13.0)$ & $9(42.9)$ \\
III & $5(21.7)$ & $8(38.1)$ \\
IV & $9(39.1)$ & $4(19.0)$ \\
\hline
\end{tabular}

followed by a gastroscopy if no cause is revealed $(19,20)$. For example, Wilcox et al (18) designed a prospective clinical study for IDA in which colonoscopy is followed by gastroscopy. In contrast, a study in Taiwan reported an equal number of gastric and colorectal cancer diagnoses (5), while a study in Korea identified that gastric cancer cases were much more frequent than colorectal cancer cases (21). This

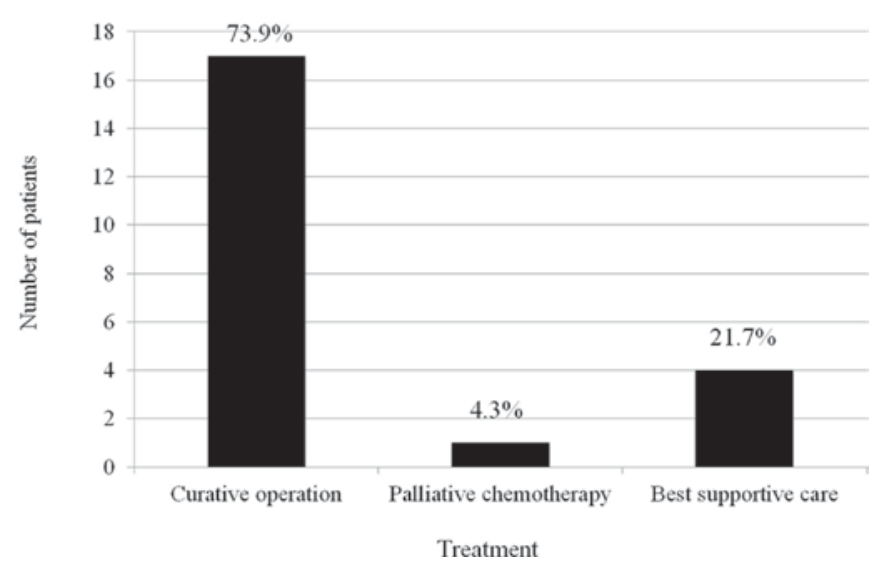

Figure 3. Treatment of identified colorectal cancer cases. From a total of 23 patients identified as having colorectal cancer in the present study, 17 patients $(73.9 \%)$ underwent curative surgery, 1 patient was administered palliative chemotherapy, and 5 patients received best supportive care.

discrepancy may have resulted from geographical differences, as colorectal cancer is observed at a much higher rate than gastric cancer in western countries. This may suggest a need for the consideration of geographical and ethnic differences in an approach to IDA (21). The present study, based on data from Japan, demonstrated approximately equal numbers of gastric and colorectal cancer patients. Taken together, this evidence suggests that in Asian countries, gastric cancer is more likely to be a cause of IDA compared with Western countries.

From the prospect of staging and resectability, $60 \%$ of patients who had their cancer detected through IDA examination presented with cancer that was at stage III or less, based on the TNM classification system, and therefore exhibited curative resectability. Gastrointestinal cancer may lead to IDA by causing chronic inflammation and active chronic bleeding, associated with ulcer formation (22). Based on this concept, cancer may be found prior to metastasis at a resectable stage when endoscopy is performed on IDA patients. This is supported by the present study; numerous patients presented 
with gastrointestinal cancer suitable for curative surgery despite the malignancy being identified in examinations for IDA. Thus, even when patients cannot receive a full check-up for further investigation of IDA, examination for the detection of cancer is highly recommended based on the present study. As modern capsule endoscopy and CT colonography techniques also contribute to the detection of cancer $(23,24)$, a combination of these different modalities is recommended to allow an increased rate of gastrointestinal malignancies to be detected in patients with IDA.

The limitation of the present study is its retrospective nature; not all the patients who visited the hospital during the period were examined for IDA, which would be the ideal procedure for a study on IDA-associated malignancy.

In conclusion, in the present study, malignancies were found in 50 patients with IDA (14.4\%). 24 of these patients exhibited gastric cancer while 23 exhibited colorectal cancer. The majority of the cancers were resectable, and curative surgery, including endoscopic treatment, was performed. The preparation of a practical IDA investigation program consisting of several modalities is required.

\section{References}

1. McLean E, Cogswell M, Egli I, Wojdyla D and de Benoist B: Worldwide prevalence of anaemia, WHO vitamin and mineral nutrition information system, 1993-2005. Public Health Nutr 12: 444-454, 2009.

2. Rockey DC and Cello JP: Evaluation of the gastrointestinal tract in patients with iron-deficiency anemia. N Engl J Med 329: 1691-1695, 1993.

3. Goddard AF, McIntyre AS and Scott BB: Guidelines for the management of iron deficiency anaemia. British Society of Gastroenterology. Gut 46 (Suppl 3-4): IV1-IV5, 2000.

4. Lindsay JO, Robinson SD, Jackson JE and Walters JR: The investigation of iron deficiency anemia-a hospital based audit. Hepatogastroenterology 46: 2887-2890, 1999.

5. Ho CH, Chau WK, Hsu HC, Gau JP, You JY and Chen CC: Predictive risk factors and prevalence of malignancy in patients with iron deficiency anemia in Taiwan. Am J Hematol 78: 108-112, 2005.

6. James MW, Chen CM, Goddard WP, Scott BB and Goddard AF: Risk factors for gastrointestinal malignancy in patients with iron-deficiency anaemia. Eur J Gastroenterol Hepatol 17: 1197-1203, 2005

7. Napal JJ, Hernández JL, Alonso J and Casuso E: Differential factors of tumor etiology for iron deficiency anemia of probable gastrointestinal origin. Rev Clin Esp 209: 265-269, 2009 (In Spanish).

8. Droogendijk J, Beukers R, Berendes PB, Tax MG, Sonnenveld P and Levin MD: Screening for gastrointestinal malignancy in patients with iron deficiency anemia by general practitioners: An observational study. Scand J Gastroenterol 46: 1105-1110, 2011.
9. Khadem G, Scott IA and Klein K: Evaluation of iron deficiency anaemia in tertiary hospital settings: Room for improvement? Intern Med J 42: 658-664, 2012.

10. Gomollon F and Gisbert JP: Anemia and digestive diseases: An update for the clinician. World J Gastroenterol 15: 4615-4626, 2009.

11. Domínguez-Ayala M, Díez-Vallejo J and Comas-Fuentes A: Missed opportunities in early diagnosis of symptomatic colorectal cancer. Rev Esp Enferm Dig 104: 343-349, 2012.

12. Stagnitti A, Barchetti F, Barchetti G, Pasqualitto E, Sartori A, Glorioso M, Gigli S, Buonocore V, Monti ML, Marini A, et al: Preoperative staging of colorectal cancer using virtual colonoscopy: Correlation with surgical results. Eur Rev Med Pharmacol Sci 19: 1645-1651, 2015.

13. Guyatt GH, Oxman AD, Ali M, Willian A, Mcllroy W and Patterson C. Laboratory diagnosis of iron-deficiency anemia: An overview. J Gen Intern Med 7: 145-153, 1992.

14. Mankodi S, Hayee BH, O' Donohue J and Reffitt D: Anaemia investigation in practice: Inappropriate, cost inefficient with a risk of missing gastrointestinal cancer. Can we improve? Clin Med (Lond) 10: 115-118, 2010.

15. Sobin LH, Gospodarowicz MK and Wittekind C: TNM Classification of Malignant Tumours. 7 edition. John Wiley \& Sons, Incorporated, pp74-77, 102-105, 2011.

16. Benson AB 3rd, Venook AP, Cederquist L, Chan E, Chen YJ, Cooper HS, Deming D, Engstrom PF, Enzinger PC, Fichera A, et al: Colon Cancer, Version 1, 2017, NCCN Clinical Practice Guidelines in Oncology. J Natl Compr Canc Netw. 3: 370-398, 2017.

17. Ajani JA, D'Amico TA, Almhanna K, Bentrem DJ, Chao J, Das P, Denlinger CS, Fanta P, Farjah F, Fuchs CS, et al: Gastric Cancer, Version 3.2016, NCCN Clinical Practice Guidelines in Oncology. J Natl Compr Canc Netw. 10: 1286-1312, 2016.

18. Wilcox CM, Alexander LN, Straub RF and Clark WS: A prospective endoscopic evaluation of the causes of upper GI hemorrhage in alcoholics: A focus on alcoholic gastropathy. Am J Gastroenterol 91: 1343-1347, 1996.

19. Sayer JM and Long RG: A perspective on iron deficiency anemia. Gut 34: 1297-1299, 1993.

20. Killip S, Bennett JM and Chambers MD: Iron deficiency anemia. Am Fam Physician 75: 671-678, 2007.

21. Yun GW, Yang YJ, Song IC, Park KU, Baek SW, Yun HJ, Kim S, Jo DY and Lee HJ: A prospective evaluation of adult men with iron-deficiency anemia in Korea. Intern Med 50: 1371-1375, 2011.

22. Logan EC, Yates JM, Stewart RM, Fielding K and Kendrick D: Investigation and management of iron deficiency anaemia in general practice: A cluster randomised controlled trial of a simple management prompt. Postgrad Med J 78: 533-537, 2002.

23. Johnson CD, Chen MH, Toledano AY, Heiken JP, Dachman A, Kuo MD, Menias CO, Siewert B, Cheema JI, Obregon RG, et al: Accuracy of CT colonography for detection of large adenomas and cancers. N Engl J Med 359: 1207-1217, 2008.

24. Van Gossum A, Munoz-Navas M,Fernandez-Urien I, Carretero C, Gay G, Delvaux M, Lapalus MG, Ponchon T, Neuhaus H, Philipper M, et al: Capsule endoscopy versus colonoscopy for the detection of polyps and cancer. N Engl J Med 361: 264-270, 2009. 